\title{
TRUST IN PARTICIPATORY ACTION COMMUNITY-ENGAGED PARTNERSHIPS: RELATIONSHIPS AND HISTORIC TRAUMA MATTER
}

BARBARA PIERCE, JOAN CARLSON, WANDA THRUSTON, PAIGE KLEMME, ANDREW FULTZ, NICOLE OGLESBY, MARY STUDLEY, AND VAL TATE

ABSTRACT

University-community participatory action partnerships can be mutually beneficial. Universities often work alongside communities to establish new and innovative community-based programming and research that are intended to benefit communities from these efforts. However, mistrust has been found to be a major issue in creating and maintaining strong relationships. This paper will marry a model of trust that forms when partners exhibit relational capital, relational embeddedness, and transparency within the principles of trauma-informed care as established by the Substance Abuse Mental Health Services Administration (SAMHSA) (2014).

A group of university researchers and community activists/organizers analyzed their work on a project to bring a community-engaged participatory action design team intervention to develop and implement trauma-responsive care in an established transitional African American community located in a large urban Midwestern city. Through our analysis we identified three major reasons for mistrust: objectification of community members; lack of real change in the community; and lack of transparency. Additionally, we found that paying attention to power differentials between the university researchers and community partners is key. Major findings around best practices mirrored the SAMHSA trauma-informed care principles and included developing "not just trust but trusting relationships," sharing "voice and choice" with all who seek to participate, understanding the historical trauma within the community, using cultural guides and long-time seasoned community organizers to facilitate processes, "showing up" and being interested in the community beyond the research or intervention by finding a way to give back to the community beyond the project.

KEYWORDS: Community-engaged participatoryaction research; Trust; Trauma

TRUST IN PARTICIPATORY ACTIONS COMMUNITY-ENGAGED PARTNERSHIPS: RELATIONSHIPS AND HISTORIC TRAUMA MATTER

Establishing trust in partnerships is a hallmark of good practice for university researchers who work in the field of community-engaged participatory action (CEPA) intervention research (Khodyakov, Mikesell, Schraiber, Booth, \& Bromley, 2016; Israel, Schultz, Parker, \& Becker, 2001). Medical and research mistrust is common in the United States, especially in communities of color. Two well-known incidents of past research that led to mistrust are the Tuskegee Study of Untreated Syphilis in the Negro Male (Katz, Kegeles, Kressin, Green, Wang, James, Russell, \& Claudio, 2006) and cervical cancer cell research study which appropriated the cell-line of Henrietta Lacks (Skloot, 2010) without her permission or 
compensation. In the community in which our research team is working, a community grandmother described this mistrust as, "You people keep coming into our community and promising to help us but all you ever do is collect your data and leave. We don't even know what your data says." It is not surprising that African American communities are especially wary. Yet, in a study that identified people's willingness to participate in research, Katz et al., 2006, surveyed 1,133 adult Black, Hispanic, and Non-Hispanic White individuals and identified Blacks were 1.8 times more likely than Whites to express fear of participating in research. However, there was no statistically significant difference in actual willingness to participate in biomedical research. In addition to the past unethical medical research practices, fear and mistrust stems from not acknowledging systematic oppression that has resulted in historical trauma and ongoing trauma experienced in predominately lowincome communities of color. Current communityengaged researchers must work to undo this fear and mistrust. Using participatory action processes may help to some degree however, establishing and maintaining trust remains a key issue.

To help researchers develop, implement, and evaluate CEPA interventions, this paper will marry a theory of partnership trust (Pierce, McGuire \& Howes, 2015) with principles of trauma-informed practice (SAMHSA, 2014) to identify best practices in CEPA research using the example of one community project which the author team is working. To be clear, our definition of CEPA is working in deep partnership with community stakeholders to identify issues and interventions as defined by the stakeholders to ameliorate a community issue. For this work to occur university and community stakeholders must establish and maintain trusting partnerships.

Trust, as defined here, is the mutual and complementary respect that partners have so that each can perform their work with integrity (Mayer, Davis, \& Shooreman, 1995). Becerra, Lunnan \& Huemer (2008) studied trust in partnerships and identified strong partnerships as having the ability to share explicit and tacit or implicit information. This sharing happens when people feel comfortable enough to form relationships by working together on shared processes (Polanyi, 1967) in a transparent manner. It is when community partners share their "insider knowledge and experience" within a community that the day-today work of participatory action community-engaged projects occurs and forms trust. However, trust is easily eroded and the three components of trust -relational capital (relationships), relational embeddedness (working together on processes), and transparency -- must be ever present (Pierce, et al., 2015; Hall, Imburgia, Jaggers, Pierce, Bloomquist, Richardson, Danh, \& Hensel, 2017). In universitycommunity partnerships, absence of trust erodes the work together and leads to the decay of the partnership (Becerra, et al. 2008). A case study completed by Pierce, et al. (2015) identified the rise, fall and rise again of a large university-agency partnership over the course of a number of years possibly due to issues of lack of trusting relationships, and especially transparency and working together daily to accomplish recognized goals. Further, Hall, et al. (2017) has identified similar results in establishing and maintaining trusting research relationship 
partnerships within a university-agency research relationship.

In communities that experience high oppression and historical mistrust of university researchers, partnerships may be able to facilitate mutually beneficial research to improve conditions for the community. Yet, historical trauma is ever present in many communities in which researchers work and must be acknowledged and addressed. Historical trauma occurs when groups of people have experienced "subjugation" by the dominant societal group (Sotero, 2009, p. 99). Sotero's (2009) model of historical trauma suggests that four elements are present in these groups: overwhelming violence, segregation or displacement, economic deprivation, and cultural dispossession. Given the history of slavery in the African American population with its violence, segregation, deprivation and cultural dispossession, this population group certainly has experienced historical trauma. In addition, given the alarming treatment of this population by researchers, it is not surprising that participation with researchers is fraught with difficulty and leads to the need for trusting and trauma-responsive research practices in order to partner authentically with communities to improve the health or well-being of their community.

Trust and attending to historical trauma are two trauma-informed principles that have been endorsed by the Substance Abuse Mental Health Services Administration (SAMHSA) (2014) who have been integrally involved in educating the public about trauma in general (Harris and Fallot, 2001). These principles based upon the work of Harris \& Fallot (2001) and Elliot, Bjelajac, Fallot, Markoff, \& Reed,
(2005) include: safety; trustworthiness and transparency; peer support; collaboration and mutuality; empowerment-voice and choice; and attention to cultural, historical, and gender issues. Further, these principles identified and tested in many different community settings appear to be generalizable and, we argue, inform development of trusting and trauma-responsive CEPA partnerships.

METHOD

This study examines participatory research practices of our community-engaged partnership with a historical African American community and analyzes responses to questions around concerns and best practices regarding the university and community relationship needed for this project. Thematic analysis was conducted on answers to the two questions posed to the team by the team leaders. The research team, all authors of this paper, essentially formed a virtual focus group to discuss concerns and best practices for CEPA on this project to bring trauma-responsive interventions to the identified community. The research team was asked to respond to the following questions:

What are the major areas of concern for people in the community regarding working with university researchers?

$>$ What are the main best practices that university researchers can do to enhance partnership with the community?

Thematic analysis included line-by-line and axial coding on the quotations in the transcribed data. Further analysis used the constant comparison 
approach within and across data points (Braun \& Clark, 2006).

This project is bounded by the work of this research team between 2016 and present and centers on the initiation of a project to bring trauma responsive services to one African American community. The case method overarches this paper (Stake, 2005) while content thematic analysis was used to explain results of concerns and best practices.

\section{Case Setting}

The work of this research team had its origins in a health fair planning group as three of the university researchers participated in the development of a health fair for the community during the summer of 2016. In developing the health fair with various community partners including residents of the community, it became clear that members of the community were frightened by the overwhelming violence and poverty in their community as well as the lack of ability to cope with the trauma that they, and especially the children in the community, were experiencing. Further exploration of this concern indeed led to a member of the community asking for trauma-responsive expertise. Researchers then identified a broader team of community engagement specialists who work daily within the community to develop a Learning Collaborative Project in order to bring trauma-responsive services to agencies working with children and families in the community. The research team convened a major stakeholder meeting to listen to community needs. Themes based on these needs were identified and reported back to the community. The research team extended project participation applications to community agencies who wished to work with the Learning Collaborative. Few community agencies actually applied and only a few people from those agencies began participating. Out of this, however, came an enlightening small group community discussion around historical trauma in their community that identified ways to bridge gaps between researchers and the community. As a result of this discussion, the research team expanded their team to include more community members and began to pay close attention to political forces both personal and community-wide which serve to confound work in the community or erode relational capital. The research team continued open communication (transparency) and work within the community on other projects (relational embeddedness), used cultural guides and community engagement staff more diligently, and paid attention to partnering using these new trust forming changes. Researchers recruited four community agency teams with which to work. Those community-based teams became energized and ready to work on the Learning Collaborative and continue this work today to bring trauma-responsive practices to schools and community.

\section{RESULTS}

\section{Demographics}

The focus group members include 7 participants; 6 are female, 4 are Caucasian and 3 are African American. There are 2 doctoral students, 4 community organizers, and one researcher. The other researcher on the team conducted the data collection and analysis and therefore did not participate in the focus group. 
All quotations in this results section are directly reported from the data and represent the answers to the two focus group questions. We endorse the practice of grounding results in direct quotations from participants.

Table 1. Themes of Concerns and Best Practices

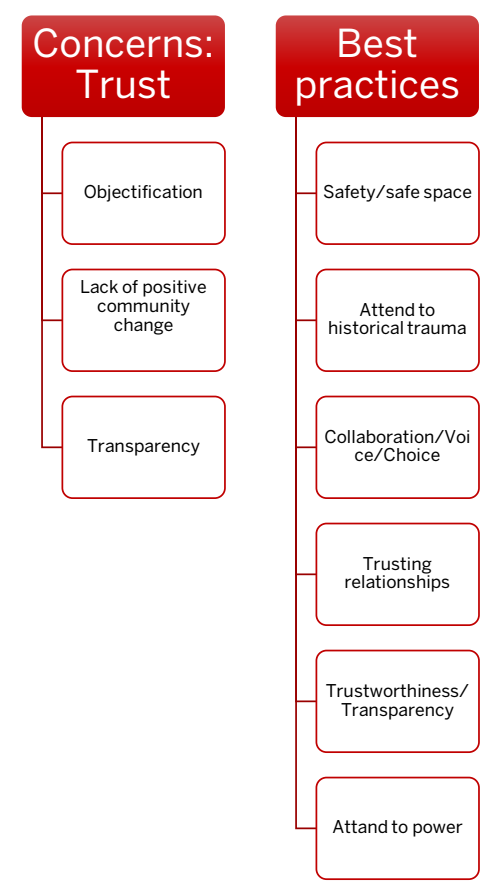

\section{Question 1 -- Major areas of concern: Trust}

Overwhelmingly, the team expressed that the major area of concern for people in the community is lack of trust. This is expressed in three areas of mistrust:

objectification, lack of positive community change, and lack of transparency in reporting data.

Five of 7 focus group participants identified that lack of trust due to objectification by university researchers is a major concern for them mainly because community members report feeling like objects to be used for a purpose. One participant noted, "Historically, many researchers have taken from the community for their own benefit and not necessarily for the benefit of the community. Often times community members are weary of being 'used' for data purposes only for a journal article.” Another noted "the greatest concern for individuals in a community is being made an object of study versus being seen as a dynamic and evolving member of a community." The understanding that researchers have an agenda of their own rather than helping to create an agenda which comes from within the community leads to the sense of being objectified, as well.

"Unintentional objectification by researchers led to a community with understandable trust issues," remarked one research team participant. Clearly another team member noted, "The community, first and foremost, wants to be recognized as an active, equal partner in all endeavors with university researchers." "The 'know it all' attitude that university researchers have" creates deficit reactions and leads to objectification, as well.

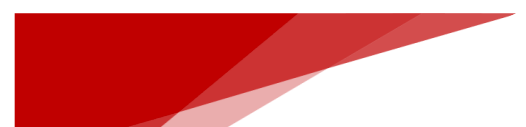

One participant noted, "Historically, many researchers have taken from the community for their own benefit and not necessarily for the benefit of the community. Often times community members are weary of being 'used' for data purposes only for a journal article." Another noted "the greatest concern for individuals in a community is being made an object of study versus being seen as a dynamic and evolving member of a community." 


\section{Erosion of trust also evolves from not} producing positive change within the community. "Often the findings do not serve the community in a way of producing real change," noted one participant. Another, strongly stated, "I have heard community members express concerns that once the researchers left, the funding and programs also left, so then the community ends up back where they started, but the researchers have their data." This selfish attitude then does not leave sustainable change. "Once the university completes involvement they leave behind a gap in services." "They generate a great deal of conversation but no real solutions get implemented ... a bunch of talk and no action."

Participants also discussed the community attitude toward not receiving reports back on data collected within the community which leads to trust issues due to lack of transparency. "Some community members have voiced their opinions in the past and their suggestions have been ignored" which leads to gaps in transparency and not hearing all of the voices in the community that erodes their trust further.

\section{Question 2 -- Best practices to enhance CEPA}

The themes related to best practices emerged as creating safety/safe space; attention to historical trauma; collaboration/empowerment/voice and choice; create and maintain trusting relationships; being trustworthy and transparent; and attending to power differentials.

The research team members reported the creation of safety or safe space was a foundational skill of CEPA work and offered various ways in which to do this. Creation of this space involves ideas such as "having a meal together;" "providing transportation;" "hiring community members or researchers who look like the community;" "paying attention to power dynamics;" avoiding the "savior complex;" and "engaging in cultural humility."

Attending to historical trauma is also a major theme in this project in particular. Research team members indicated that "learning the history of the community" and "practicing cultural humility" is important. One research team member said, "We must see the community as people, not as a project, not as a program." Inherent in this statement is the sense that the community has experienced trauma as a result of being "just a project." Another mentioned "community members are taking a risk by inviting outsiders into their community when past partnerships have the community members feeling like they were exploited." Being a good collaborator and promoting empowerment through voice and choice within the CEPA project is vital to its success. "Find out what the community wants and give it to them," and another stated that community members have "a plethora of wisdom, knowledge and skills, that help us see their priorities and vision." "We need to embrace their expertise." "The community is the expert!" Another clearly stated, "Ignoring voices decreases trust and increases disengagement." Collaboration also involved hiring for the project "from within the community." Further, inclusion of team members from the community endorsed power sharing with the community team members to provide trainings and opportunities to "lead from within."

Creating and maintaining trusting relationships is another theme crucial to best practice. The team, building trusting relationships over 
time, "becomes involved in the community by attending things that are not necessarily tied to the research.”

"Building authentic relationships with the community consists of spending time with and in the community. Attending events, forums, and gatherings as an informal participant sans title. I know from experience that I put in a lot of evenings and weekends in one particular community as a part of the relationship building stage."

Trusting relationships are built through sharing power and voice and through a "dialogic engagement that all voices are respected and heard." Relationship is best expressed, says one team member, by "training and empowering them ... investing in the relationships from an authentic standpoint" so the findings of the research are "owned by the community and the researchers alike."

The last theme involves being trustworthy and transparent. While the data endorses ideas such as using non-jargon and transparent language it is also important to note the inherent power differential that is important to name and claim as a result of the work. Being trustworthy typically means that researchers should say what they are going to do and follow through by doing it. However, also found in the data was the idea that researchers should be particularly careful not to take advantage of the community participants. Trustworthy in the data here means that as researchers we "do not leave the community" and that we provide "sustainable interventions that do not disappear when the researchers leave the project." It is so important that "the interventions that are developed need to be practical and do not leave the community without the possibility of sustainable services.” In addition, the research team endorsed that "change needs to be real" for the community.

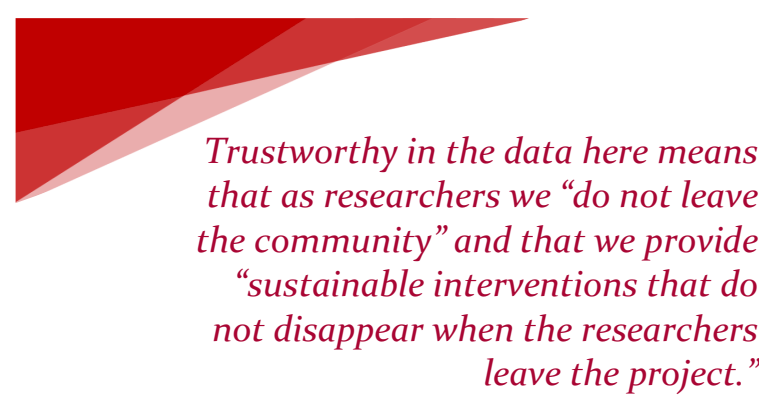

Encompassing all aspects of these data is the theme of power. Researchers and community organizers all noted that a major difference between the university participants and the community participants is power. "Researchers who adopt a stance of conducting research 'on' a community perpetuate an imperialistic form of research that seeks to 'fix' and 'help.' Instead, researchers should adopt a stance of conducting research 'with' a community ... the goals and purposes have to be decided ideally by the community in conjunction with the researchers." Other aspects of power include timing of meetings, who is in the room, sharing of processes and data, and "meeting members of the community where they are in the community in small groups on their turf ... demonstrates that they are the priority."

\section{DISCUSSION}

Identification of trust as the major theme that emerged from the research team is not surprising. The literature makes clear that trust building in universitycommunity partnerships appears to be paramount. In the instance of this case study however, the identification of various aspects of trust is novel 
learning. In CEPA partnerships the identification of mistrust due to objectification, lack of positive community change, and lack of transparency appear unique to the research relationship. While these three areas of mistrust may be unique to this particular community, it seems unlikely. Historically, as we have already described, researchers have not been trustworthy partners nor have they named the historical trauma inherent in the process. While many social science researchers genuinely want to implement positive community change, reflecting on, and defining the mistrust issue in terms of historical trauma has not been common. It is true that researchers need to collect data as part of the process. However, to aid in community acceptance and trust building, while combating the effects of historical trauma, the researcher must make the data collection as well as analysis processes clear and include community members in the process. Further, this practice helps to sustain change over time. Being completely transparent about the relationship and process from the beginning may also increase trust. Understanding the avenues of mistrust enhances understanding of university-community partnerships and provides researchers with methods of community engagement to prevent mistrust from the beginning of a new project.

Given the level of historical trauma inherent in the target community of this study, it is clear the research team members were focused on finding best practices to help to ameliorate the community's historical trauma in this particular project. Yet, the research team members were not asked to answer the questions posed to them from a trauma-responsive stance. In fact, they were asked to answer the questions as CEPA researchers. Interestingly, as the themes emerged from the answers to the best practices question, these practices mirrored most of the basic trauma-informed care principles as endorsed by SAMHSA. Further, while peer support, a hallmark of the SAMHSA principles did not emerge, another important principle did -- that of power differentials. The SAMHSA trauma-responsive principles did not use the term "power", yet the literature from which SAMHSA derived them clearly identified power as an issue (Harris \& Fallot, 2001). The CEPA literature outlines equal partnerships as one way to cope with power differentials in the researcher-community relationship (Khodyakov, et al. 2016; Israel, 2001). We strongly endorse that research teams reflect on power and identify ways to share power equally with their community partners. Being trustworthy and developing trusting, collaborative partnerships can help with power sharing.

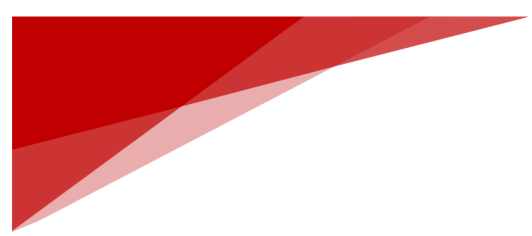

We strongly endorse that research teams reflect on power and identify ways to share power equally with their community partners. Being trustworthy and developing trusting, collaborative partnerships can help with power sharing.

The analysis of the data strongly identified the theme of trustworthiness and transparency. A trustworthy partner does not objectify, is transparent, and helps the community to produce positive change. 
Essentially, being a trustworthy partner could then ameliorate the three forms of community mistrust identified by this research team.

Our research team brought a quality improvement intervention strategy to the community to enhance trauma services. Inherent in our practice is teaching our Learning Collaborative teams to use this intervention independently thereby enhancing the capacity of the community. Essential practices then related to this finding include being genuinely interested in positive change within the community; building capacity by collaborating with as well as teaching the community members to use any tested interventions independently; and producing sustainable change.

A trustworthy university partner also learns the history of the community and takes historical trauma into consideration. They engage in building collaborative trusting relationships with members of the community within a trauma-responsive manner.

Creation of relationships must occur in safe spaces in which partners can speak freely and honestly (voice and choice) about needs and concerns as well as attending to power differentials in relationships. Developing a process where both the university and communities identify and define common terms up front and set appropriate group process standards helps partners feel equal and safe. It also builds collaboration and provides for empowered voice and choice. Using common non-jargon language, or if necessary defining or explaining issues or concepts, helps the community to understand interventions and/or research processes. Strategically embedding researchers across a room full of community stakeholders can also allow for relationships to form. Eating meals together as part of the relationship building process has been a good way for our team to get to know our partners more personally. Further, our research team includes community organizers and people of color, one of whom currently lives in the community, and others who have long standing familiarity and trust built within the community. The above practices fulfill our promise to the community to help devise supportive trauma strategies. This effort also begins the process of healing from past experiences with researchers.

Within a trauma-responsive frame and given the level of historical and present day trauma within our served community, we endorse identifying the strengths of the community and using those strengths to enhance the partnership. As one of our team reported, there is "lots of wisdom in communities." Trauma-responsive practice is inherently strengthsbased and encourages the paradigm shift in thinking from what is wrong with a community to what happened to them. When we use community strengths and build upon those we build capacity.

Given the literature around the need to establish trust in CEPA research projects we posit that researchers have failed to name the mistrust inherent in many communities as historical trauma, nor have they taken a trauma-responsive approach to the creation and maintenance of CEPA projects. Our strong recommendation based on our experience with this project includes attending to the inherent trauma in communities. It is important to note that many communities in which historic trauma is of concern are also communities that cope daily with oppression, 
poverty, racism, classism, and community violence.

When social scientists fail to take trauma into consideration they risk re-traumatizing the very people they hope to help.

The SAMHSA principles of creating safety, building trustworthiness and trusting partnerships, collaborating, empowering, and identifying strengths as expressed in our data with the inclusion of attending to power differentials, may help to mitigate further trauma by research teams.

\section{LIMITATIONS AND IMPLICATIONS}

This case study reflects two questions related to a mutual CEPA project in which a team of researchers and community partners are participating. As such, the results are not generalizable per se. However, our finding that identification of areas of mistrust will help to inform the construct of trust for future measurement considerations is important. Further, the identification of the SAMHSA trauma principles as important best practices leads to practice implications for CEPA researchers and provides future research questions related to historical trauma of communities, along with the trauma caused by research within communities, and important practices to mitigate such trauma.

\section{Conclusion}

This case study of one CEPA project to bring trauma responsive programming to an African American community led to the identification of a deeper definition of the construct of trust and best practices. These findings appear to mirror many of the SAMHSA trauma principles. Future research might consider studying the trust construct more closely and identifying and studying trauma more closely in community-engaged participatory action research projects.

\section{REFERENCES}

Becerra, M., Lunnan, R., \& Huemer, L. (2008). Trustworthiness, risk, and the transfer of tacit and explicit knowledge between alliance partners. Journal of Management Studies, 45(4), 691-713.

Braun, V. \& Clark, V. (2006). Using thematic analysis in psychology. Qualitative research in psychology, 3, 77-101.

Elliot, D.E., Bjelajac, P., Fallot, R.D., Markoff, L.S., and Reed, B.G. (2005). Trauma-informed or trauma-denied: Principles and implementation of trauma-informed services for women. Journal of Community Psychology, 33(4), 461477 .

Hall, J., Imburgia, T., Kim. J., Jaggers, J., Pierce, B., Bloomquist, K., Richardson, E., Danh, M., \& Hensel, D. (2017). Partnership for multimethod evaluation in child welfare: Title IV-E Waiver Demonstration Program. Child Welfare, 95, 5, 59-78.

Harris, M. and Fallot, R. (2001). Using trauma theory to design service systems. New Directions for Mental Health Services, 89. Jossey Bass.

Israel, B. A., Schulz, A. J., Parker, E. A., \& Becker, A. B. (2001). Community-based participatory research: Policy recommendations for promoting a partnership approach in health research. Education for Health, 14(2), 182-197. 
Retrieved from

http://depts.washington.edu/ccph/pdf_files/Ed ucforHealthIsrael.pdf

Katz, R., Kegeles, S., Kressin, N. R., Green, B. L., Wang, M. Q., James, S. A., Russell, S. L., \& Claudio, C. (2006). The Tuskege legacy project:

Willingness of minorities to participate in biomedical research. Journal of Health Care for the Poor and Underserved, 17, 4, 698-715. 10.1353/hpu.2006.0126

Khodyakov, D., Mikesell, L., Schraiber, R., Booth, M., \& Bromley, E., (2016). On using ethical principles of community-engaged research in translational science Translational Research, 171, 52-62.

doi.org/10.1016/j.trsl.2015.12.008

Mayer, R. C., Davis, J. H., \& Schoorman, D. (1995). An integrative model of organizational trust. Academy of Management Review, 20, 709-734.

Pierce, B. * McGuire, L., \& Howes, P. (2015). Ready, Set, go...again: Renewing an academy-agency child welfare partnership. Journal of Social Work Education Supplement, 2(51), 239-251. doi: https://doi.org/10.1080/10437797.2015.1072424

Polanyi, M. (1967). The tacit dimension. Garden City, NY: Anchor.

Skloot, R. (2010). The Immortal Life of Henrietta Lacks. New York: Crown Publishing Group.

Sotero, M. M. (2006). A conceptual model of historical trauma: Implications for public health practice and research. Journal of Health Disparities Research and Practice, 1, 1, 93-108. http://ssrn.com/abstract=1350062

Stake, R. E. (2005). Qualitative case studies. In N.
Denzin, \& Y. Lincoln (Eds.), Handbook of qualitative research ( $3^{\text {rd }}$ ed.). Thousand Oaks, CA: Sage.

Substance Abuse and Mental Health Services Administration. SAMHSA's Concept of Trauma and Guidance for a Trauma-Informed Approach. HHS Publication No. (SMA) 14-4884. Rockville, MD: Substance Abuse and Mental Health Services Administration, 2014. 